\title{
The degree of damage to plants of different cultivars of faba bean (Vicia faba L.) and pea (Pisum sativum L.) by Deroceras reticulatum (O.F. Müller)
}

\section{Stopień uszkodzenia roślin różnych odmian bobiku (Vicia faba L.) i grochu (Pisum sativum L.) przez Deroceras reticulatum (O.F. Müller)}

\author{
Jan Kozłowski ${ }^{1}$, Monika Jaskulska ${ }^{1}$, Maria Kozłowska ${ }^{2}$
}

\section{Summary}

The aim of this study was to estimate susceptibility of faba bean and pea cultivars to slugs of the species Deroceras reticulatum. Experiments were carried out in controlled conditions on sprouting seeds and on plants at the 3- or 4-leaf stage of development. The study included plants of nine faba bean cultivars and eleven pea cultivars, which were exposed to grazing by slugs. From the cultivars of faba bean listed in the national register of agricultural plants, cultivars with high and low tannin contents were selected for this study. It was determined which of the cultivars exhibit higher or lower sensitivity to $D$. reticulatum. Severe damage was recorded in the case of germinating seeds of the Granit cultivar of faba bean and the Mentor cultivar of pea, and plants of the Leo cultivar of faba bean and the Mecenas and Muza cultivars of pea. The obtained information will be used in the selection of cultivars for cultivation in areas with a high risk of slugs.

Key words: Deroceras reticulatum; cultivars of faba bean and pea; damages

\section{Streszczenie}

Celem przeprowadzonych badań była ocena wrażliwości odmianowej bobiku i grochu na ślimaki Deroceras reticulatum. Badania wykonano w kontrolowanych warunkach, na kiełkujących nasionach i roślinach w fazie rozwojowej 3-4 liści. Obiektem badań były rośliny dziewięciu odmian bobiku i jedenastu odmian grochu, które eksponowano na żerowanie ślimaków. Spośród odmian bobiku wymienianych w krajowym rejestrze roślin rolniczych, do badań wybrano odmiany o wysokiej i niskiej zawartości tanin. Na podstawie przeprowadzonych badań wyodrębniono odmiany mniej lub bardziej wrażliwe na $D$. reticulatum. Do silniej uszkadzanych należały kiełkujące nasiona bobiku odmiany Granit i nasiona grochu odmiany Mentor oraz rośliny bobiku odmiany Leo i rośliny grochu odmiany Mecenas i Muza. Uzyskane informacje będą wykorzystane w doborze odmian do uprawy na obszarach zagrożonych przez ślimaki.

Słowa kluczowe: Deroceras reticulatum; odmiany bobiku i grochu; uszkodzenia

\footnotetext{
${ }^{1}$ Instytut Ochrony Roślin - Państwowy Instytut Badawczy Zakład Zoologii

Władysława Węgorka 20, 60-318 Poznań

${ }^{2}$ Uniwersytet Przyrodniczy w Poznaniu

Katedra Metod Matematycznych i Statystycznych

Wojska Polskiego 28, 60-637 Poznań

*corresponding author: m.jaskulska@iorpib.poznan.pl
} 


\section{Wstęp / Introduction}

Bobik i groch, podobnie, jak inne rośliny strączkowe, są wartościowym pokarmem dla różnych gatunków ślimaków z rodziny Arionidae i Agriolomacidae (South 1992; Gebauer 2002). Dominującym gatunkiem w uprawach tych roślin jest pomrowik plamisty - Deroceras reticulatum (O.F. Müller) (Gastropoda: Pulmonata: Agriolimacidae), który żeruje i uszkadza wszystkie organy roślin. Największe uszkodzenia powoduje na wysianych nasionach i na młodych roślinach, bezpośrednio po wschodach. Znaczne szkody wyrządza także na strąkach roślin bobowatych (Fabaceae) uszkadzając owocolistki i nasiona (Gebauer 2002). Badania nad wielkością uszkodzeń różnych gatunków i odmian roślin strączkowych przez ślimaki dotyczyły głównie: łubinu, koniczyny, lucerny i fasoli (Dirzo i Harper 1982; South 1992; Aguiar i Wink 1999, 2005; Byers 2002; Port i Ester 2002; Brooks i wsp. 2003; Kozłowski i Jaskulska 2014). Natomiast niewiele wiadomo na temat stopnia uszkodzenia bobiku i grochu przez ślimaki.

Celem przeprowadzonych badań była ocena wrażliwości odmianowej bobiku i grochu na ślimaki Deroceras reticulatum.

\section{Materiały i metody / Materials and methods}

W badaniach wykorzystano ślimaki $D$. reticulatum, zebrane wiosną 2015 roku z ogrodów w okolicy Poznania oraz nasiona dziewięciu odmian bobiku i jedenastu odmian grochu siewnego uzyskane od komercyjnych hodowców. Wśród odmian bobiku były cztery odmiany wysokotaninowe: Granit, Bobas, Neptun, Optimal (0,398-0,499 mg tanin/g s.m.) i pięć odmian niskotaninowych: Albus, Amulet, Kasztelan, Leo, Olga $(0,032-0,035 \mathrm{mg} \operatorname{tanin} / \mathrm{g}$ s.m.) (Domański i Osiecka 2014). Badane odmiany grochu to siedem odmian użytkowych (Akord, Audit, Batuta, Lasso, Mecenas, Medal, Mentor) i cztery pastewne (Model, Muza, Sokolik, Turnia).

Zebrane ślimaki umieszczono na podłożu $5 \mathrm{~cm}$ warstwy ziemi w plastikowych pojemnikach, w temperaturze $16^{\circ} \mathrm{C}$. Dieta ślimaków zawierała: liście kapusty, bulwy ziemniaków, korzenie marchwi oraz otręby pszenne $\mathrm{z}$ dodatkiem węglanu wapnia, które wymieniano, co trzy dni. Przed każdym testem ślimaki głodzono przez 48 godzin i ważono.

Doświadczenia wykonano na kiełkujących nasionach i na młodych roślinach, które eksponowano na żerowanie ślimaków. Nasiona trzymano przez dwa dni w warunkach wysokiej wilgotności w celu ich spęcznienia i skiełkowania. Następnie umieszczono je na zwilżonej bibule filtracyjnej w plastikowych pojemnikach $(20 \times 16 \times 13 \mathrm{~cm})$, po 12 nasion każdej odmiany w jednym pojemniku. Do pojemników wkładano po jednym osobniku $D$. reticulatum. Średnia masa ślimaków w pojemnikach z nasionami bobiku wynosiła 0,54 g, a $\mathrm{z}$ nasionami grochu 0,42 g. Rośliny w fazie 3-4 liści, uzyskane z nasion wysianych w skrzynkach ogrodniczych, posadzono w $5 \mathrm{~cm}$ warstwie próchniczno-gliniastej ziemi $\mathrm{w}$ wentylowanych plastikowych pojemnikach $(26 \times 26 \times 14 \mathrm{~cm})$. Po dwóch dniach umieszczono w nich po jednym osobniku $D$. reticulatum o średniej masie $0,37 \mathrm{~g}$ dla bobiku oraz $0,46 \mathrm{~g}$ dla grochu. Po włożeniu ślimaków wszystkie pojemniki umieszczono w kabinie klimatycznej, w temperaturze powietrza $17^{\circ} \mathrm{C}$, RH $70 \pm 3 \%$ i długości dnia 12 godzin. Jeden raz dziennie oceniano uszkodzenia nasion oraz roślin według 5-stopniowej skali $(0 ; 25 ; 50 ; 75$ i $100 \%$ uszkodzonej powierzchni). Dla nasion i roślin wszystkich odmian bobiku i grochu wykonano po 6 powtórzeń. Uzyskane wyniki poddano analizie wariancji ANOVA i zastosowano test Fishera przy poziomie istotności $\alpha=0,05$.

\section{Wyniki i dyskusja / Results and discussion}

Objawy żerowania D. reticulatum na kiełkujących nasionach i roślinach wszystkich odmian bobiku i grochu były podobne. Ślimaki zjadały korzonki zarodkowe oraz bielmo i zarodki nasion. W znacznie mniejszym stopniu zjadane były hipokotyle, liścienie oraz zawiązki liści. Na roślinach w fazie 3-4 liści ślimaki wygryzały otwory w liściach, a w niektórych przypadkach zjadały pojedyncze liście w całości.

\section{Uszkodzenia odmian bobiku}

Po pierwszym dniu żerowania ślimaków, najsilniej uszkodzone były nasiona odmiany Granit, a nasiona odmiany Leo nie były w ogóle uszkodzone (tab. 1). Od trzeciego do siódmego dnia obserwacji istotnie silniej uszkodzone były nasiona odmiany Granit w porównaniu do nasion odmian Optimal i Bobas. Nasiona odmian z wysoką zawartością tanin były zarówno silnie (Granit 0,482 mg/g s.m.), jak i słabo (Optimal - 0,499 mg/g s.m. i Bobas - 0,398 mg/g s.m.) uszkadzane przez D. reticulatum. Wskazuje to, że taniny zawarte w nasionach badanych odmian bobiku nie miały istotnego wpływu na wielkość ich uszkodzeń przez ślimaki. Taką zależność stwierdzono w badaniach dotyczących preferencji pokarmowej Arion subfuscus (Draparnaud) w stosunku do siewek wierzb (Salix sericea i $S$. eriocephala) (Fritz i wsp. 2001; Albrectsen i wsp. 2004). W przypadku tych roślin, stężenie tanin wahało się w zakresie od 50 do $100 \mathrm{mg} / \mathrm{g}$ s.m. (Fritz i wsp. 2001), czyli było wielokrotnie wyższe niż $\mathrm{W}$ nasionach badanych $\mathrm{w}$ tej pracy odmian bobiku. Sugeruje to, że zawartość tych związków w nasionach bobiku była zbyt niska, aby wywołać ich deterentny wpływ na $D$. reticulatum.

Podobnie, jak w przypadku nasion, pierwsze istotne różnice między wielkością uszkodzeń roślin odmian bobiku przez ślimaki stwierdzono po jednym dniu ich żerowania (tab. 2). Od pierwszego do ostatniego dnia, istotnie silniej uszkadzane były rośliny bobiku odmiany Leo w porównaniu do roślin odmiany Granit (tab. 2). Wskazuje to, że rośliny odmiany Leo są preferowane przez ślimaki i wykazują wyższą wrażliwość na uszkodzenia niż pozostałe badane odmiany.

\section{Uszkodzenia odmian grochu}

Podczas pierwszej doby żerowania $D$. reticulatum, istotnie silniej uszkadzane były nasiona grochu odmian 
Tabela 1. Uszkodzenia nasion różnych odmian bobiku (Vicia faba L.) przez Deroceras reticulatum i wyniki testu Fishera przy poziomie istotności $\alpha=0,05$

Table 1. Damage caused by Deroceras reticulatum to seeds, for different cultivars of faba bean (Vicia faba L.), and the results of Fisher's test at a significance of $\alpha=0.05$

\begin{tabular}{l|c|c|c|c|c|c|c}
\hline \multirow{2}{*}{$\begin{array}{c}\text { Odmiany } \\
\text { Cultivars }\end{array}$} & \multicolumn{9}{|c}{ Dni żerowania ślimaków - Days of slug feeding } \\
\cline { 2 - 9 } & 1 & 2 & 3 & 4 & 5 & 6 & 7 \\
\hline Albus & $0,3 \mathrm{ab}$ & $2,4 \mathrm{a}$ & $4,2 \mathrm{ab}$ & $4,2 \mathrm{ab}$ & $5,9 \mathrm{abc}$ & $6,2 \mathrm{ab}$ & $6,2 \mathrm{ab}$ \\
\hline Amulet & $1,4 \mathrm{abc}$ & $2,8 \mathrm{a}$ & $5,5 \mathrm{ab}$ & $5,5 \mathrm{ab}$ & $7,3 \mathrm{abc}$ & $7,6 \mathrm{ab}$ & $8,3 \mathrm{ab}$ \\
\hline Bobas & $1,0 \mathrm{abc}$ & $2,1 \mathrm{a}$ & $3,1 \mathrm{a}$ & $3,1 \mathrm{a}$ & $3,5 \mathrm{a}$ & $4,2 \mathrm{a}$ & $4,9 \mathrm{a}$ \\
\hline Granit & $2,4 \mathrm{c}$ & $3,5 \mathrm{a}$ & $6,9 \mathrm{~b}$ & $7,3 \mathrm{~b}$ & $9,0 \mathrm{c}$ & $9,7 \mathrm{~b}$ & $10,1 \mathrm{~b}$ \\
\hline Kasztelan & $2,1 \mathrm{bc}$ & $3,5 \mathrm{a}$ & $3,1 \mathrm{a}$ & $4,9 \mathrm{ab}$ & $5,5 \mathrm{abc}$ & $6,6 \mathrm{ab}$ & $6,9 \mathrm{ab}$ \\
\hline Leo & $0,0 \mathrm{a}$ & $2,1 \mathrm{a}$ & $4,2 \mathrm{ab}$ & $7,3 \mathrm{~b}$ & $7,3 \mathrm{abc}$ & $8,0 \mathrm{ab}$ & $8,0 \mathrm{ab}$ \\
\hline Neptun & $0,3 \mathrm{ab}$ & $2,4 \mathrm{a}$ & $4,9 \mathrm{ab}$ & $4,9 \mathrm{ab}$ & $6,2 \mathrm{abc}$ & $6,9 \mathrm{ab}$ & $6,9 \mathrm{ab}$ \\
\hline Olga & $1,7 \mathrm{abc}$ & $3,1 \mathrm{a}$ & $6,9 \mathrm{~b}$ & $6,9 \mathrm{~b}$ & $8,0 \mathrm{bc}$ & $8,3 \mathrm{ab}$ & $9,0 \mathrm{~b}$ \\
\hline Optimal & $0,3 \mathrm{ab}$ & $1,4 \mathrm{a}$ & $3,1 \mathrm{a}$ & $3,1 \mathrm{a}$ & $3,8 \mathrm{ab}$ & $4,9 \mathrm{a}$ & $4,9 \mathrm{a}$ \\
\hline
\end{tabular}

Wartości w kolumnach oznaczone tą samą literą nie różnią się istotnie

Values in columns marked with the same letters do not differ significantly

Tabela 2. Uszkodzenia roślin w fazie 3-4 liści różnych odmian bobiku (Vicia faba L.) przez Deroceras reticulatum i wyniki testu Fishera przy poziomie istotności $\alpha=0,05$

Table 2. Damage caused by Deroceras reticulatum to plants at the 3-4 leaf stage, for different cultivars of faba bean (Vicia faba L.), and the results of Fisher's test at a significance of $\alpha=0.05$

\begin{tabular}{l|c|c|c|c|c|c|c}
\hline \multirow{2}{*}{$\begin{array}{c}\text { Odmiany } \\
\text { Cultivars }\end{array}$} & \multicolumn{7}{|c}{ Dni żerowania ślimaków - Days of slug feeding } \\
\cline { 2 - 9 } & 1 & 2 & 3 & 4 & 5 & 6 & 7 \\
\hline Albus & $2,5 \mathrm{ab}$ & $3,3 \mathrm{ab}$ & $5,0 \mathrm{ab}$ & $7,5 \mathrm{a}$ & $8,3 \mathrm{abc}$ & $10,0 \mathrm{a}$ & $10,0 \mathrm{ab}$ \\
\hline Amulet & $2,5 \mathrm{ab}$ & $3,3 \mathrm{ab}$ & $4,2 \mathrm{ab}$ & $4,2 \mathrm{a}$ & $5,8 \mathrm{abc}$ & $5,8 \mathrm{a}$ & $5,8 \mathrm{a}$ \\
\hline Bobas & $4,2 \mathrm{ab}$ & $4,2 \mathrm{ab}$ & $5,8 \mathrm{ab}$ & $6,7 \mathrm{a}$ & $10,8 \mathrm{bc}$ & $10,8 \mathrm{a}$ & $11,7 \mathrm{ab}$ \\
\hline Granit & $0,8 \mathrm{a}$ & $0,8 \mathrm{a}$ & $1,7 \mathrm{a}$ & $3,3 \mathrm{a}$ & $4,2 \mathrm{a}$ & $7,5 \mathrm{a}$ & $8,3 \mathrm{ab}$ \\
\hline Kasztelan & $2,5 \mathrm{ab}$ & $4,2 \mathrm{ab}$ & $5,0 \mathrm{ab}$ & $5,0 \mathrm{a}$ & $7,5 \mathrm{abc}$ & $9,2 \mathrm{a}$ & $10,0 \mathrm{ab}$ \\
\hline Leo & $5,0 \mathrm{~b}$ & $5,8 \mathrm{~b}$ & $7,5 \mathrm{~b}$ & $9,2 \mathrm{a}$ & $11,7 \mathrm{c}$ & $12,5 \mathrm{a}$ & $14,2 \mathrm{~b}$ \\
\hline Neptun & $1,7 \mathrm{ab}$ & $1,7 \mathrm{ab}$ & $2,5 \mathrm{a}$ & $3,3 \mathrm{a}$ & $5,0 \mathrm{ab}$ & $8,3 \mathrm{a}$ & $9,2 \mathrm{ab}$ \\
\hline Olga & $0,8 \mathrm{a}$ & $2,5 \mathrm{ab}$ & $5,0 \mathrm{ab}$ & $5,8 \mathrm{a}$ & $6,7 \mathrm{abc}$ & $8,3 \mathrm{a}$ & $8,3 \mathrm{ab}$ \\
\hline Optimal & $0,8 \mathrm{a}$ & $3,3 \mathrm{ab}$ & $5,0 \mathrm{ab}$ & $6,7 \mathrm{a}$ & $7,5 \mathrm{abc}$ & $8,3 \mathrm{a}$ & $9,2 \mathrm{ab}$ \\
\hline
\end{tabular}

Wartości w kolumnach oznaczone tą samą literą nie różnią się istotnie

Values in columns marked with the same letters do not differ significantly

Mecenas i Mentor w porównaniu do nasion pozostałych odmian (tab. 3). Od drugiego do siódmego dnia, większe uszkodzenia obserwowano na nasionach odmiany Mentor niż na nasionach odmiany Medal. Ponadto od trzeciego dnia silniej uszkadzane były nasiona odmiany Sokolik w porównaniu do nasion odmian Audit i Akord. Łączna analiza wielkości uszkodzeń nasion podczas całego okresu żerowania ślimaków wykazała, że bardziej wrażliwe na uszkodzenia były nasiona odmiany Mentor w porównaniu do nasion odmiany Medal.

Po pierwszym dniu żerowania ślimaków na roślinach, istotnie silniej uszkadzane były odmiany Mecenas i Muza w porównaniu do pozostałych odmian (tab. 4). Od drugiego dnia słabiej uszkadzane od roślin wymienionych odmian były rośliny odmiany Akord, przy czym po sześciu i siedmiu dniach, różnice te nie były statystycznie istotne. Generalnie, istotnie większe uszkodzenia w wyniku żerowania ślimaków, wystapiły na roślinach odmiany Mecenas i Muza w porównaniu do roślin odmiany Akord.
Przyczyną różnej wrażliwości odmianowej bobiku i grochu na uszkodzenia przez $D$. reticulatum była prawdopodobnie zróżnicowana zawartość substancji odżywczych występujących w badanych odmianach. Zależność taką stwierdzono, na przykład dla nasion odmian pszenicy o różnej zawartości azotu ogólnego i cukrów (Port i Port 1986; Spaul i Eldon 1990). Wykazano, że odmiany pszenicy o wyższej zawartości tych składników są preferowane przez $D$. reticulatum. Duże znaczenie mogły mieć także wtórne metabolity roślinne, które jak wiadomo ograniczają aktywność żerowania ślimaków i powodowane przez nie uszkodzenia roślin. Przykładem takich substancji są alkaloidy quinolizidynowe i pyrolizydynowe występujące w niektórych odmianach roślin z rodzaju Lupinus sp. (Fabaceae) (Aguiar i Wink 1999, 2005), alkaloidy steroidowe w odmianach ziemniaka Solanum tuberosum L. (Solanaceae) (Ester i Trul 2000) oraz cyjanogenne glikozydy w niektórych formach koniczyny białej Trifolium repens L. (Fabaceae) (Dirzo i Harper 1982). W badaniach 
Tabela 3. Uszkodzenia nasion różnych odmian grochu (Pisum sativum L.) przez Deroceras reticulatum i wyniki testu Fishera przy poziomie istotności $\alpha=0,05$

Table 3. Damage caused by Deroceras reticulatum to seeds, for different cultivars of pea (Pisum sativum L.), and the results of Fisher's test at a significance of $\alpha=0.05$

\begin{tabular}{l|c|c|c|c|c|c|c}
\hline \multirow{2}{*}{$\begin{array}{c}\text { Odmiany } \\
\text { Cultivars }\end{array}$} & \multicolumn{7}{|c}{ Dni żerowania ślimaków - Days of slug feeding } \\
\cline { 2 - 9 } & 1 & 2 & 3 & 4 & 5 & 6 & 7 \\
\hline Akord & $4,2 \mathrm{ab}$ & $7,3 \mathrm{a}$ & $11,1 \mathrm{abc}$ & $14,2 \mathrm{abc}$ & $16,0 \mathrm{abc}$ & $17,7 \mathrm{ab}$ & $19,8 \mathrm{ab}$ \\
\hline Audit & $5,2 \mathrm{ab}$ & $7,3 \mathrm{a}$ & $9,4 \mathrm{ab}$ & $12,8 \mathrm{ab}$ & $14,2 \mathrm{ab}$ & $18,4 \mathrm{ab}$ & $21,2 \mathrm{abc}$ \\
\hline Batuta & $4,9 \mathrm{ab}$ & $9,0 \mathrm{ab}$ & $14,6 \mathrm{a}-\mathrm{d}$ & $18,8 \mathrm{~b}-\mathrm{e}$ & $20,8 \mathrm{~cd}$ & $22,6 \mathrm{bc}$ & $24,3 \mathrm{~b}-\mathrm{e}$ \\
\hline Lasso & $6,6 \mathrm{ab}$ & $11,8 \mathrm{ab}$ & $17,7 \mathrm{~cd}$ & $19,4 \mathrm{~b}-\mathrm{e}$ & $22,6 \mathrm{~d}$ & $25,0 \mathrm{c}$ & $26,0 \mathrm{cde}$ \\
\hline Mecenas & $8,0 \mathrm{~b}$ & $11,8 \mathrm{ab}$ & $16,7 \mathrm{bcd}$ & $21,2 \mathrm{de}$ & $23,3 \mathrm{~d}$ & $23,6 \mathrm{bc}$ & $26,0 \mathrm{cde}$ \\
\hline Medal & $5,6 \mathrm{ab}$ & $9,4 \mathrm{ab}$ & $10,8 \mathrm{abc}$ & $15,3 \mathrm{a}-\mathrm{d}$ & $20,1 \mathrm{bcd}$ & $22,2 \mathrm{bc}$ & $24,3 \mathrm{~b}-\mathrm{e}$ \\
\hline Mentor & $8,7 \mathrm{~b}$ & $14,6 \mathrm{~b}$ & $20,8 \mathrm{~d}$ & $22,9 \mathrm{~d}$ & $25,3 \mathrm{~d}$ & $26,4 \mathrm{c}$ & $28,1 \mathrm{e}$ \\
\hline Model & $3,1 \mathrm{a}$ & $6,9 \mathrm{a}$ & $8,3 \mathrm{a}$ & $11,1 \mathrm{a}$ & $12,5 \mathrm{a}$ & $14,6 \mathrm{a}$ & $16,7 \mathrm{a}$ \\
\hline Muza & $4,5 \mathrm{ab}$ & $9,0 \mathrm{ab}$ & $15,3 \mathrm{a}-\mathrm{d}$ & $18,4 \mathrm{~b}-\mathrm{e}$ & $23,6 \mathrm{~d}$ & $26,4 \mathrm{c}$ & $27,1 \mathrm{cde}$ \\
\hline Sokolik & $5,9 \mathrm{ab}$ & $10,8 \mathrm{ab}$ & $17,4 \mathrm{~cd}$ & $22,2 \mathrm{~d}$ & $24,0 \mathrm{~d}$ & $25,3 \mathrm{c}$ & $27,4 \mathrm{de}$ \\
\hline Turnia & $6,9 \mathrm{ab}$ & $13,9 \mathrm{~b}$ & $19,4 \mathrm{~d}$ & $20,5 \mathrm{cde}$ & $20,8 \mathrm{~cd}$ & $21,5 \mathrm{bc}$ & $21,5 \mathrm{a}-\mathrm{d}$ \\
\hline
\end{tabular}

Wartości w kolumnach oznaczone tą samą literą nie różnią się istotnie

Values in columns marked with the same letters do not differ significantly

Tabela 4. Uszkodzenia roślin w fazie 3-4 liści różnych odmian grochu (Pisum sativum L.) przez Deroceras reticulatum i wyniki testu Fishera przy poziomie istotności $\alpha=0,05$

Table 4. Damage caused by Deroceras reticulatum to plants at the 3-4 leaf stage, for different cultivars of pea (Pisum sativum L.) and the results of Fisher's test at a significance of $\alpha=0.05$

\begin{tabular}{l|c|c|c|c|c|c|c}
\hline \multirow{2}{*}{$\begin{array}{c}\text { Odmiany } \\
\text { Cultivars }\end{array}$} & \multicolumn{7}{c}{ Dni żerowania ślimaków - Days of slug feeding } \\
\cline { 2 - 9 } & 1 & 2 & 3 & 4 & 5 & 6 & 7 \\
\hline Akord & $2,5 \mathrm{a}$ & $5,8 \mathrm{a}$ & $7,5 \mathrm{a}$ & $11,7 \mathrm{a}$ & $16,7 \mathrm{ab}$ & $17,5 \mathrm{a}$ & $20,0 \mathrm{a}$ \\
\hline Audit & $5,8 \mathrm{ab}$ & $10,0 \mathrm{abc}$ & $13,3 \mathrm{abc}$ & $17,5 \mathrm{ab}$ & $20,8 \mathrm{abc}$ & $22,5 \mathrm{a}$ & $25,0 \mathrm{a}$ \\
\hline Batuta & $4,2 \mathrm{a}$ & $9,2 \mathrm{ab}$ & $13,3 \mathrm{abc}$ & $18,3 \mathrm{ab}$ & $20,8 \mathrm{abc}$ & $20,8 \mathrm{a}$ & $21,7 \mathrm{a}$ \\
\hline Lasso & $4,2 \mathrm{a}$ & $7,5 \mathrm{ab}$ & $10,8 \mathrm{ab}$ & $18,3 \mathrm{ab}$ & $21,7 \mathrm{abc}$ & $25,0 \mathrm{a}$ & $29,2 \mathrm{a}$ \\
\hline Mecenas & $10,0 \mathrm{~b}$ & $15,8 \mathrm{~cd}$ & $20,8 \mathrm{c}$ & $21,7 \mathrm{~b}$ & $24,2 \mathrm{bc}$ & $26,7 \mathrm{a}$ & $28,3 \mathrm{a}$ \\
\hline Medal & $6,7 \mathrm{ab}$ & $11,7 \mathrm{a}-\mathrm{d}$ & $15,8 \mathrm{bc}$ & $18,3 \mathrm{ab}$ & $24,2 \mathrm{bc}$ & $24,2 \mathrm{a}$ & $26,7 \mathrm{a}$ \\
\hline Mentor & $5,8 \mathrm{ab}$ & $11,7 \mathrm{a}-\mathrm{d}$ & $15,8 \mathrm{bc}$ & $17,5 \mathrm{ab}$ & $20,0 \mathrm{abc}$ & $24,2 \mathrm{a}$ & $25,8 \mathrm{a}$ \\
\hline Model & $3,3 \mathrm{a}$ & $9,2 \mathrm{ab}$ & $12,5 \mathrm{ab}$ & $15,0 \mathrm{ab}$ & $19,2 \mathrm{abc}$ & $20,8 \mathrm{a}$ & $21,7 \mathrm{a}$ \\
\hline Muza & $10,8 \mathrm{~b}$ & $16,7 \mathrm{~d}$ & $17,5 \mathrm{bc}$ & $20,8 \mathrm{~b}$ & $25,8 \mathrm{c}$ & $25,8 \mathrm{a}$ & $27,5 \mathrm{a}$ \\
\hline Sokolik & $7,5 \mathrm{ab}$ & $13,3 \mathrm{bcd}$ & $15,0 \mathrm{abc}$ & $18,3 \mathrm{ab}$ & $21,7 \mathrm{abc}$ & $22,5 \mathrm{a}$ & $30,0 \mathrm{a}$ \\
\hline Turnia & $3,3 \mathrm{a}$ & $7,5 \mathrm{ab}$ & $10,0 \mathrm{ab}$ & $14,2 \mathrm{ab}$ & $14,2 \mathrm{a}$ & $17,5 \mathrm{a}$ & $23,3 \mathrm{a}$ \\
\hline
\end{tabular}

Wartości w kolumnach oznaczone tą samą literą nie różnią się istotnie

Values in columns marked with the same letters do not differ significantly

prowadzonych nad preferencją pokarmową Helix pomatia, Arion ater i D. reticulatum wykazano, że rośliny Geum urbanum, Rubus idaeus i Alchemilla vulgaris zawierające zagęszczone taniny są odrzucane przez ślimaki (Molgaard 1986). Nie stwierdzono takiej reakcji D. reticulatum na taniny występujące w badanych przez autorów roślinach bobiku, o czym wspomniano powyżej.

Uzyskane wyniki, dotyczące stopnia wrażliwości poszczególnych odmian bobiku i grochu na uszkodzenia przez D. reticulatum, stanowią podstawę dalszych badań nad opracowaniem integrowanych metod ochrony tych roślin przed ślimakami. Ważnym elementem tych metod, będzie wykorzystanie odmian tolerancyjnych i mniej wrażliwych na żerowanie ślimaków. Duże znaczenie ma poznanie zależności preferencji pokarmowej $D$. reticulatum od składu biochemicznego roślin, warunkujących ich wrażliwość na uszkodzenia. Poznanie tych zależności będzie przedmiotem przyszłych badań.

\section{Wnioski / Conclusions}

1. Odmiany bobiku, jak i grochu wykazują różną wrażliwość na uszkodzenia przez $D$. reticulatum. Wskazuje to na różne wymagania pokarmowe tego ślimaka. 
2. Poziom uszkodzeń nasion i roślin tych samych odmian obydwu gatunków roślin jest zróżnicowany.

3. Zawartość tanin w nasionach bobiku nie ma istotnego wpływu na wielkość ich uszkodzeń przez ślimaki.
4. Bardziej wrażliwe na uszkodzenia sa nasiona bobiku odmiany Granit i nasiona grochu odmiany Mentor oraz rośliny bobiku odmiany Leo i rośliny grochu odmiany Mecenas i Muza. Na obszarach zasiedlonych przez tego ślimaka odmiany te nie powinny być uprawiane.

\section{Literatura / References}

Aguiar R., Wink M. 1999. Mollusc-deterrent activity of lupin alkaloids. p. 97-98. In: Proceeding 9th International Lupin Conference. Germany, Klink/Mültriz, 20-24 June 1999. International Lupin Association, Canterbury, New Zeeland, 481 pp.

Aguiar R., Wink M. 2005. How do slugs cope with toxic alkaloids? Chemoecology 15 (3): 167-177.

Albrectsen B.R., Gardfjell H., Orians C.M., Murray B., Fritz R.S. 2004. Slugs, willow seedlings and nutrient fertilization: intrinsic vigor inversely affects palatability. Oikos 105: 268-278. DOI: 10.1111/j.0030-1299.2004.12892.x

Brooks A.S., Crook M.J., Wilcox A., Cook R.T. 2003. A laboratory evaluation of the palatability of legumes to the field slug Deroceras reticulatum Müller. Pest Management Science 59 (3): 245-251.

Byers R.A. 2002. Agriolimacidae and Arionidae as pests in lucerne and other legumes in forage systems of north-eastern North America. p. 325-335. In: "Molluscs as Crop Pests" (G.M. Barker, ed.). Landcare Research Hamilton, New Zealand, CABI Publishing, UK, $468 \mathrm{pp}$.

Dirzo R., Harper J.L. 1982. Experimental studies on slug-plant interactions. IV The performance of cyanogenic and acyanogenic morphs of Trifolium repens in the field. Journal of Ecology 70: 119-138.

Domański P.J., Osiecka A. 2014. Pastewne. s. 105-135. W: „Lista opisowa odmian roślin rolniczych 2014. Burak, ziemniak, oleiste i włókniste pastewne” (E.S. Gacek, red.). COBORU, Słupia Wielka, 146 ss.

Ester A., Trul R. 2000. Slug damage and control of field slug (Deroceras reticulatum (Müller)) by carvone in stored potatoes. Potato Research 43 (3): 253-261.

Fritz R.S., Hochwender C.G., Lewkiewicz D.A., Bothwell S., Orians C.M. 2001. Seedling herbivory by slugs in a willow hybrid system: developmental changes in damage, chemical defense, and plant performance. Oecologia 129 (1): 87-97.

Gebauer J. 2002. Survival and food choice of the grey field slug (Deroceras reticulatum) on three different seed types under laboratory conditions. Anzeiger für Schädlingskunde. Journal of Pest Science 75: 1-5.

Kozłowski J., Jaskulska M. 2014. The effect of grazing by the slug Arion vulgaris, Arion rufus and Deroceras reticulatum (Gastropoda: Pulmonata: Stylommatophora) on extent of damage to leguminous plants and other small-area crops. Journal of Plant Protection Research 54 (3): 258-266.

Molgaard P. 1986. Food plant preferences by slugs and snails: a simple method to evaluate the relative palatability of the food plants. Biochemical Systematics Ecology 14 (1): 113-121.

Port R., Ester A. 2002. Gastropods as pests in vegetables and ornamental crops in Western Europe. p. 337-352. In: "Molluscs as Crop Pests" (G.M. Barker, ed.). Landcare Research Hamilton, New Zealand, CABI Publishing, UK, 468 pp.

Port C.M., Port G.R. 1986. The biology and behaviour of slugs i relation crop damage and control. Agricultural Zoology Reviews 1: 255-299.

South A. 1992. Terrestrial Slugs: Biology, Ecology, and Control. Chapman and Hall, London, 444 pp.

Spaul A.M., Eldon S. 1990. Is it possible to limit slug damage using choice winter wheat culivars? p. 703-708. In: Proccedings of The Brighton Crop Protection Conference: Pest and Diseases. Vol. 2. UK, Brighton, 17-20 November 1986, 865 pp. 